\title{
Historia civil y poesía, certeza y verdad en Francis Bacon
}

\section{Civil history and poetry, certainty and truth in Francis Bacon}

\begin{abstract}
Silvia MANZO
Instituto de Investigaciones en Humanidades y Ciencias Sociales (UNLP - CONICET). Facultad de Humanidades y Ciencias de la Educación. Universidad Nacional de La Plata - Argentina
\end{abstract}

Recibido: 20/03/2014

Aceptado: 03/07/2014

\section{Resumen}

Este artículo se propone estudiar elementos claves de la teoría de la historia y de la práctica de la historia civil de Francis Bacon en lo que concierne a la verdad y la certeza de la narrativa histórica. Compara sus teorías de la historia y de la poesía, así como la relación que ellas tienen con la certeza, la verdad y la ficción. Para eso principalmente analiza dos clases de escritos. Por un lado, los textos programáticos en los que el autor presenta sus ideas sobre la historia y la poesía. Por otro lado, analiza sus textos completos e incompletos de historia civil en los que actuó como historiador. Además, este artículo considerará la obra baconiana teniendo en cuenta como marco de referencia la historiografía inglesa renacentista y moderna. Concluye que aunque la historia y la poesía constituyen dos ramas distintas en la clasificación baconiana del saber, tienen importantes elementos en común, en consonancia con la teoría de la poesía desarrollada por su contemporáneo Philip Sidney. Así es como Bacon incorporó elementos ficcionales en su narrativa histórica y adoptó un particular modo de distinguir en ella lo cierto de lo conjetural. Esta posición con respecto a la historia civil contrasta fuertemente con la metodología que Bacon propuso para la 
historia natural, la cual para alcanzar la certeza recomienda enfáticamente excluir cualquier tipo de relato ficcional al reportar los hechos de la naturaleza.

Palabras clave: historiografía renacentista y moderna, historia civil, poesía, certeza, probabilidad, ficción, Francis Bacon.

\begin{abstract}
This article aims at studying key components of Francis Bacon's theory of history and of his work as practitioner of civil history, particularly in regard to truth and certainty in historical narratives. It compares Bacon's theories of history and poetry, and the way in which he conceives their relation to certainty, truth and fiction. It analyzes mainly two sorts of writings. On the one hand, it investigates the programmatic texts where Bacon's views of history and poetry are developed. On the other hand, it examines the finished and unfinished civil histories written by Bacon as historian. In addition, the article evaluates Bacon's stances against the background of Renaissance and early modern English historiography. It concludes that although history and poetry constitute separate branches in Bacon's classification of learning, they share important elements, in keeping with the view of poetry maintained by his contemporary Philip Sidney. Thus, Bacon included fictional patterns in his historical narrative and distinguished certainties from conjectures in a particular way. This attitude towards civil history shows a strong contrast to Bacon's methodology for natural histories, which, in order to reach certainty, staunchly recommends to exclude any fictional narrative in reporting the facts of nature.
\end{abstract}

Keywords: Renaissance and early modern historiography, civil history, poetry, certainty, probability, fiction, Francis Bacon

\title{
Historiadores y anticuarios: la narración de las causas en la historia civil
}

Hasta comienzos del siglo XVII la historia estaba dominada por un paradigma humanista que la consideraba una parte de la retórica destinada a brindar enseñanzas a partir de los ejemplos del pasado. El objetivo del historiador no era buscar nuevos hechos a ser relatados sino más bien exponer de manera persuasiva y bella los hechos ya conocidos, lo cual suponía la inclusión tanto de discursos ficticios como también de enseñanzas y reflexiones morales. A partir 
del siglo XVII, surgieron distintas alternativas teóricas y nuevas prácticas que fueron remplazando este ideal historiográfico. ${ }^{1}$ Como veremos a lo largo de esta exposición, la teoría de la historia civil de Bacon constituye una síntesis de esas nuevas tendencias de la historiografía de su tiempo. ${ }^{2}$

Uno de los rasgos más sobresalientes de la teoría baconiana es el mandato de dar cuenta de las causas de los hechos históricos. A diferencia de lo que Bacon propone con respecto a la historia natural, en la que el objetivo fundamental es la recolección de los hechos de la naturaleza en sus distintos estados para servir como base a la filosofía natural que es la encargada del descubrimiento de las causas a través de la inducción, en lo que se refiere a la historia civil Bacon sostiene que en su forma más desarrollada la historia civil debe no sólo reportar los "hechos y acciones de los hombres" sino también sus causas. ${ }^{3}$ La historia perfecta añade las causas a los "eventos y las acciones desnudas" recogidas en otros tipos de relatos históricos que por su propia naturaleza están exentos de "los motivos o los planes, los consejos, los discursos, los pretextos, las ocasiones y los otros caminos hacia la acción". ${ }^{4}$ Bacon establece una suerte de jerarquía entre las tres clases fundamentales de historia que distingue en su clasificación de la historia civil. En los escalones inferiores sitúa los "memoriales" y las "antigüedades". Los primeros son historias en estado rudimentario y se dividen en dos clases. Por un lado, los "comentarios" que se caracterizan por exponer la sucesión y la conexión "desnuda" de los eventos y las acciones, sin aludir a sus causas ni a las intenciones que condujeron a ellos. Por otro lado, se encuentran los "registros" que a su vez son de dos tipos: los fastos y las cronologías, que presentan una lista de eventos ordenados temporalmente; las actas (solennitates actorum) que recopilan edictos y decretos, cartas, discursos y documentos públicos en general. ${ }^{5}$ Por su parte, las "antigüedades" son presentadas como "historias deformadas", "reliquias y vestigios" que por casualidad se salvaron del naufragio del tiempo y fueron rescatadas gracias al cuidado y la constancia de hombres laboriosos y sagaces. ${ }^{6}$ Se trata de registros históricos muy variados: monumentos, monedas,

\footnotetext{
${ }^{1}$ Levy (2004) 252. Las referencias a las obras de Bacon que remiten a Bacon (1989), son indicados en las notas como "SEH" seguido de número de tomo y página; las que remiten a diversos volúmenes de la edición The Oxford Francis Bacon consignados en la bibliografía son indicados en las notas con la abreviatura "OFB" seguida de número de tomo y página.

${ }^{2}$ Levy (2004) 256-257.

${ }^{3}$ Para un análisis detallado de las diferencias entre historia natural e historia civil con respecto a las causas vd. Manzo (2012).

${ }^{4}$ Advancement of Learning (OFB IV 65) (hay traducción española vd. Bacon (1988)); De augmentis scientiarum (SEH I 506).

${ }^{5}$ Advancement of Learning (OFB IV 65-66); De augmentis scientiarum (SEH I 505-506).

${ }^{6} \mathrm{Ib}$.
} 
nombres, etimologías, proverbios, tradiciones, notas privadas, fragmentos de libros de historia y de libros que, aunque no sean de historia, ofrecen información relevante para el historiador. Como decíamos, tanto los memoriales como las antigüedades son, según Bacon, manifestaciones inferiores de la historia.

Haciendo una comparación de la historia con la pintura, ${ }^{7}$ Bacon nos dice que los memoriales son "pinturas incompletas" a las que les falta terminación, mientras que las antigüedades son pinturas mutiladas y deformadas por el paso del tiempo. La especie más alta de la historia, que Bacon denomina "historia perfecta" retomando una denominación corriente en la historiografía francesa de su época, ${ }^{8}$ es la pintura completa y no deformada, que se sirve de las otras para alcanzar su objetivo. El historiador de la historia perfecta se dedica a interpretar el material proporcionado por las antigüedades y los memoriales, para ofrecer un relato racional y no idealizado de los hechos, ${ }^{9}$ cosa que las formas imperfectas de historia no llegan a hacer, no porque sean eventualmente defectuosas, sino por su propia naturaleza.

La clasificación baconiana de la historia civil recoge algunos desarrollos de la historiografía de su tiempo. En la historiografía inglesa de los inicios de la Modernidad, se produjo un proceso de creciente diferenciación de la actividad realizada por los "historiadores", por un lado, y por los "anticuarios", por el otro. La distinción de estos dos nombres para designar a cada grupo no era del todo estricta, ya que los anticuarios se consideraban a sí mismos historiadores y ya desde la década de 1630 las palabras "anticuario" e "historiador" se usaban como sinónimos. ${ }^{10}$ Más allá de este detalle terminológico, lo cierto es que tanto en la práctica como en la teoría historiográfica se diferenciaban unos de los otros. Los anticuarios de la época eran por lo general eruditos abocados a la investigación y la búsqueda exhaustiva de nuevas fuentes, a las que examinaban con técnicas cada vez más sofisticadas en pos de ponderar su nivel de credibilidad y determinar su verdadero origen en el tiempo. Su forma de trabajo y sus técnicas eran deudoras de la crítica textual humanista a la que sumaron de

\footnotetext{
${ }^{7}$ En carta al Lord Canciller Ellesmere, Bacon dice que las estatuas y las pinturas son "historias mudas", mientras que las historias son "pinturas parlantes." Carta a Ellesmer, 2 de abril de 1605 SEH X 249-250.

${ }^{8}$ La obra clásica de referencia a este respecto es Huppert (1970).

${ }^{9}$ Con esto quiero señalar la concordancia de Bacon con la idea de historia de Maquiavelo: exponer los hechos como son y no como deben ser. Advancement of Learning (OFB IV 44). Este compromiso es expresado en relación con la caracterización de Enrique VII, en Henry VII (OFB VIII 8): "I have not flattered him [Henry VII ], but took him to life as well as I could, sitting so far off, and having no better light."

${ }^{10}$ Esta tesis formulada por Smith Fussner (1962) ha sido cuestionada. Para un panorama general de las interpretaciones y discusiones sobre lo que se ha denominado la "Revolución histórica inglesa", vd. Woolf (1987).
} 
algún modo el espíritu escrutador de la nueva ciencia natural, por entonces en ciernes. ${ }^{11}$ La práctica de los anticuarios no era completamente novedosa -en rigor tenía antecedentes en la Antigüedad, pero incorporaba actividades que para la mayor parte de los historiadores eran ajenas al verdadero quehacer de la historia. Para los historiadores tradicionales, el cometido del historiador consistía en interpretar los hechos ya conocidos y construir una narración a partir de ellos: no se trataba de buscar nueva información, de husmear en distintas formas de registros del pasado ni de controlar si las fuentes disponibles eran fidedignas. Ocupados por lo general en escribir la historia de Inglaterra, estos historiadores del periodo Tudor pensaban que los hechos principales ya estaban disponibles en numerosas fuentes, medievales y renacentistas. Tales fuentes habitualmente repetían y recopilaban lo que fuentes anteriores habían registrado. Los historiadores creían que no había necesidad alguna de sumar más hechos a la narrativa histórica ni de corroborar los que ya habían sido relatados y repetidos por una sucesión de textos autorizados y dignos de crédito.

Así las cosas, en tiempos de Bacon las diferencias entre historiadores y anticuarios fomentaron reflexiones teóricas y debates acerca de la verdadera naturaleza de la historia, de sus objetivos y de sus métodos. En este contexto, la posición de Bacon se inclina claramente a favor de la actividad de los historiadores tradicionales sin dejar por eso de reconocer el valor de los aportes producidos por los anticuarios. ${ }^{12}$ En efecto, por un lado reconoce que el arduo trabajo de rescate de los vestigios de la historia realizado por los anticuarios es objeto del favor de los hombres y de cierta reverencia. Incluso admite que este trabajo puede llegar a reemplazar los relatos fabulosos de los orígenes de las distintas naciones. Sin embargo, también piensa que el oficio de los anticuarios constituye una actividad elitista que a pocos interesa y que, por tal motivo, tiene escasa autoridad. ${ }^{13}$ Bacon subraya una vez más que la forma más alta de la historia debe articular los eventos del pasado con sus causas. Por eso juzga que quienes, como los anticuarios, no se dedican a realizar esta interpretación

\footnotetext{
${ }^{11}$ Sobre la crítica de la evidencia histórica en el Renacimiento y la modernidad temprana vd. Popper (2011). El estudio de Popper señala que Bacon aplicó para la reforma de la historia natural los procedimientos críticos promovidos por la historia civil "empírica" en el siglo XVI. Sin embargo, no nota que, curiosamente, como mostraremos en este artículo, Bacon no aplicó en la práctica estos procedimientos para la producción de sus propias historias civiles, ni hizo referencia a este aspecto en su metodología para la historia civil.

${ }^{12}$ Dean (1941) 169-170; Woolf (1987) 27; 45.

${ }^{13}$ Este comentario no está en el Advancement of Learning. Fue agregado en el De augmentis scientiarum (SEH I 506), quizá porque en 1623, cuando Bacon compone esta última obra, el debate entre historiadores y anticuarios era más intenso que en 1605, año de la publicación del Advancement of Learning.
} 
de los hechos históricos en términos causales cumplen más bien una función complementaria de asistencia al historiador, quien sí se ocupa de escribir la "historia perfecta". ${ }^{14}$

El énfasis de Bacon en la búsqueda de las causas por parte del historiador forma parte de una tendencia de la historiografía Tudor en la que él mismo se destacó como uno de sus principales promotores. Según F. Levy, la investigación de las causas de los hechos históricos es un rasgo constitutivo de una nueva forma de la escritura histórica que surge hacia fines del siglo XVI en la historiografía Tudor. Esta nueva forma, que Levy denominó "historia política", se propuso a sí misma enseñar la prudencia política en base a la razón. Desde esta perspectiva, explicar los fenómenos históricos, apelando a la providencia divina como su causa primera y general, no resulta útil para entender el porqué de las decisiones políticas. En cambio, para alcanzar ese objetivo es fundamental tomar en consideración las "causas secundarias" involucradas en las decisiones de los actores humanos. Tales causas eran de diversa índole, aunque fundamentalmente se tomaban en consideración las psicológicas, las políticas, las sociales y las geopolíticas. ${ }^{15}$ Cabe agregar que este rasgo de la "historia política" toma como modelo la historia de Tácito, un autor de referencia para la historiografía isabelina que continuó siéndolo en la época Estuardo. ${ }^{16}$ Este interés por la causalidad histórica se ocupaba preferentemente de la narrativa de los procesos más que de las narrativas biográficas, dado que el propósito de la "historia política" era aplicar máximas derivadas de la historia a casos futuros en el quehacer político.

La teoría baconiana considera que el historiador debe exponer las causas particulares de eventos particulares. La contingencia y la variedad propias de las conductas humanas y de las circunstancias políticas hacen imposible una repetición uniforme de patrones de acción. Sin embargo, pueden darse situaciones semejantes en el pasado, en el presente y en el futuro. Así, Bacon asume que toda acción humana tiene un porqué único y singular, de manera que no existen regularidades causales que, a la manera de leyes necesarias y universales, subsumen efectos particulares uniformes ocurridos a lo largo del tiempo. Precisamente, la tarea de la historia perfecta es dar con ese porqué único y singular para otorgarle un sentido a la acción "desnuda". Así es cómo el simple inventario de hechos que proveen los memoriales y los documentos recupera-

\footnotetext{
${ }^{14}$ Wormald (1993) 58; Levy (2004) 255.

${ }^{15}$ Levy (2004) 237-238.

${ }^{16}$ Vickers (1998) xiv-xviii; Zagorin (1998) 215. Sobre Bacon y Tácito, vd. Berry (1971) 302303; Benjamin, (1965) y Levy (2004) 253. Sobre Tácito en la historiografía de la época vd. Salmon (1989).
} 
dos por los anticuarios puede transformarse en una narrativa racional. Las intenciones y los planes de un agente, como así también las circunstancias concomitantes de sus acciones, deben ser registradas por el historiador de modo tal que el relato histórico brinde una guía para la acción futura. ${ }^{17} \mathrm{La}$ historia instruye y hace a los hombres de acción más sabios porque les indica cursos de acción mediante la exposición de ejemplos de otros actores y de situaciones similares que tuvieron lugar en el pasado. ${ }^{18}$ Con todo, Bacon advierte que el historiador no debe, a la manera de los humanistas, hacer comentarios y observaciones a partir de los ejemplos históricos que expone. ${ }^{19}$ Las observaciones y conclusiones deben surgir de los propios lectores. ${ }^{20}$ Probablemente aludiendo a los Discorsi de Maquiavelo, Bacon reconoce que a veces se realiza una suerte de historia mixta, que mezcla la historia con el análisis político. Pero Bacon disiente con esta práctica, ya que cree que es la filosofía y no la historia la que debe realizar una reflexión política y moral a partir de los hechos recogidos y narrados por el historiador. ${ }^{21}$

Las causas de las acciones de los hombres casi nunca son evidentes ni visibles por sí mismas. Por el contrario, deben ser inferidas a partir de hechos más evidentes. Por ello, Bacon sostiene que muchas veces el historiador necesita conjeturar las causas y las intenciones de las acciones de los hombres. Probablemente cree que una de las tareas más difíciles del historiador precisamente consiste en determinar las causas de los eventos que narra. Al mismo tiempo, seguramente es consciente de que las mayores controversias entre las diversas versiones históricas de los mismos acontecimientos políticos giran en torno a cuáles son las genuinas causas de los acontecimientos.

La apreciación que Bacon realiza sobre la función subordinada de los anticuarios con respecto a la de los historiadores es coherente con su práctica a la hora de escribir la historia. Si bien Bacon tenía contacto con anticuarios muy destacados de su tiempo como John Selden, William Camden y Robert Cotton, y también tenía acceso a los encargados de guardar los documentos de la Corona (Keepers of the Rolls), en términos comparativos es muy poco el material original que utilizó para preparar su The Historie of the raigne of King

\footnotetext{
${ }^{17}$ Una interpretación diferente puede encontrarse en Shapiro (1983) 137-138.

${ }^{18}$ Esta finalidad de la historia Bacon la señala bien explícitamente en varios pasajes de sus obras y en cartas. Vd. por ejemplo Advancement of Learning (OFB IV 10-12). Más referencias pueden encontrarse en Marwil (1976) 149-150.

${ }^{19}$ De augmentis scientiarum (SEH I 503).

${ }^{20}$ Advancement of Learning (OFB IV 70); De augmentis scientiarum (SEH I 513-514).

${ }^{21}$ Wormald (1993) 221-224.
} 
Henry the seventh. ${ }^{22}$ Entre 1621 y 1622, mientras componía esa obra, debido a la condena que recibió por cohecho Bacon tenía prohibido ir la corte, de modo que no podía acceder personalmente a archivos en los que podría haber encontrado nuevo material documental. ${ }^{23}$ Existen evidencias de que procuró obtener documentos a través de la asistencia de John Borough y Selden, y de que obtuvo diversos materiales de la colección de Cotton. ${ }^{24}$ Se especula que de la biblioteca de Cotton Bacon utilizó un texto impreso del obispo John Fisher, manuscritos originales de la Historia Regis Henrici Septimi de Bernard Andreas y otros manuscritos tanto oficiales como privados. ${ }^{25}$ Sin embargo, su relato de la historia del reinado de Enrique VII en su mayor parte se basó en textos impresos tradicionales y no se destaca ni por la novedad ni por la precisión factual. ${ }^{26}$ Su materia prima fundamental fue History of Great Britaine (1611) de John Speed, obra a la que Bacon mismo había contribuido proveyéndole al autor un boceto de la estructura que había pensado para escribir su historia de Enrique VII. Además, Bacon consultó la Anglica historia, originalmente compuesta en latín por Polidoro Virgilio, aunque al parecer se basó sobretodo en la versión inglesa libre compuesta por Edward Halle, The union of the two noble and illustrate families of Lancastre and Yorke (1548). Otra fuente destacada fue Annales of England de John Stow (1592). De menor envergadura fue su uso de las obras compuestas por Robert Fabyan, Thomas More, Francesco Guicciardini, Philip Commines y Richard Hakluyt. ${ }^{27}$ A partir de estas fuentes, en su mayor parte impresas, la History of Henry VII, siguiendo el mandato metodológico de su autor, hace una exposición seleccionando, alternando y combinando críticamente la información que ellas proveen. El resultado final es una narrativa racional de la historia y no un mero inventario de hechos.

${ }^{22}$ Para referirme a esta obra en adelante utilizaré la forma abreviada "History of Henry VII". Dean (1941) 170; Levy (2005) 218. Cabe señalar que Bacon hizo sugerencias y correcciones a la versión preliminar de los Annales de Camden en las secciones referidas a su padre, Nicholas Bacon. Vd. Kiernan, Introducción de OFB VIII xxv.

${ }^{23}$ Levy (2005) 218.

${ }^{24}$ Woolf (1984). Woolf relativiza la afirmación de Busch (1895) 416-423, según la cual Bacon no usó el material de archivo que tenía disponible en la biblioteca de Cotton. La información más actualizada a este respecto se encuentra en la reciente edición de History of Henry VII realizada por M. Kiernan. Vd. Introducción de OFB VIII xxviii-xxxii.

${ }^{25}$ Marvil (1976) 154-156; Anderson (1984) 171; Levy (2004) 258; Kiernan, Introducción de OFB VIII xxviii-xxxii.

${ }^{26}$ Zagorin (1998) 214-215; Tinkler (1996) 240-241; Clark (1974) 105. No obstante, cabe notar que History of Henry VII fue valorada en su propio tiempo y siglos después como una obra de investigación histórica rigurosa. Vd. Dean (1941) 171; Woolf (1984) 50; Wormald (1993) 59.

${ }^{27}$ Marvil (1976) 155; Vickers (1998) xi-xiv; Levy (2005) 211; Kiernan, Introducción de OFB VIII xxxii-xli. 


\section{Hechos, conjeturas y plausibilidad}

En la tarea de inferir las causas a partir de las acciones visibles en la History of Henry VII, Bacon se basa muy especialmente en el perfil psicológico de los personajes históricos involucrados. Así, presenta una suerte de monólogo interior, como un proceso en términos del cual explica las acciones manifiestas de los agentes. Esta práctica sigue una sólida tradición de la historia biográfica y se inspira en la obra de Guicciardini, uno de los historiadores más positivamente valorados por Bacon. ${ }^{28}$ Por ejemplo, cuando expone el "hecho desnudo" de la decisión de Enrique VII de coronar a su consorte Isabel de York, Bacon agrega lo que según su interpretación sería la causa de tal decisión. Expone la serie de razonamientos internos del Rey, teniendo en cuenta tanto sus características psicológicas como las circunstancias externas que tuvieron peso en su curso de acción. Bacon conjetura esas causas reinterpretando la información factual que le aportan sus fuentes, presuponiendo un perfil psicológico del Rey y dejando por lo general de lado causas de orden social, económico o incluso político. ${ }^{29} \mathrm{~A}$ lo largo del texto Bacon ofrece una suerte de retrato psicológico de Enrique, de su "naturaleza" y sus "costumbres", en el que por ejemplo se lo presenta como alguien ambicioso, calculador y disimulador, dispuesto a sembrar más la duda que la certeza respecto de sus intenciones y sus acciones. ${ }^{30} \mathrm{Su}$ interpretación de los hechos está cargada de presupuestos en esta dirección:

Pero para extirpar las raíces y las causas de conmociones semejantes en el futuro, el Rey comenzó a descubrir [...] que el haber debilitado a la Casa de York fue lo que resintió y dañó el afecto de su pueblo [hacia él]. Por ello, ya que ahora sabía demasiado como para seguir desdeñando los peligros, y dado que quería darle [al pueblo] alguna satisfacción en este sentido (aunque no fuera más que en una ceremonia), decidió finalmente proceder a la coronación de su Reina. [...] la Reina fue coronada con gran solemnidad $[\ldots]$ unos dos años después de haberse producido el matrimonio [...] lo cual constituía un lapso de tiempo llamativo e inusual, por lo que cualquiera se daba cuenta de que constituía un acto que le revolvía el estómago al Rey y que se le impuso por necesidad y por razones de Estado. ${ }^{31}$

\footnotetext{
${ }^{28}$ Berry (1971) 284; Anderson (1984) 173.

${ }^{29}$ Dean (1941) 182.

${ }^{30}$ Sigo en esto la interpretación del excelente trabajo de Anderson (1984) cap. 10.

${ }^{31}$ Henry VII (OFB VIII 30-31). Estas observaciones sobre la demora en la coronación y la repulsión que sentía el Rey no están en las fuentes y son especulaciones de Bacon. Vd. Kiernan, comentarios a Henry VII (OFB VIII 334).
} 
Bacon no dispone de información directa de las fuentes para afirmar que tal fue la serie de razones internas que movieron a Enrique para coronar a Isabel de York. Simplemente conjetura esas razones en base a sus presupuestos y en concordancia con el perfil general del Rey que sostiene a lo largo de la obra. Ahora bien, la tecnología literaria que utiliza para exponer estas causas no da indicios de que se trata de causas conjeturales. Por el contrario, las narra como si fueran un hecho tan indudable como el hecho mismo de la coronación, acreditado por sus fuentes. En cambio, en otros casos Bacon presenta como conjeturales hechos que sin embargo sus fuentes acreditan como ciertos.

¿Cuál es el criterio que Bacon utiliza en la historia civil para distinguir lo cierto de lo probable? Bacon examina sus fuentes, aunque no lo hace de la misma manera en que lo hacían los anticuarios. No se interesa por investigar rigurosamente los orígenes del texto, ni su transmisión, sus traducciones o en general su historia "material". De hecho, se han constatado algunos errores en las fuentes que Bacon reproduce aunque acaso podría haberlos corregido de haber aplicado el rigor y la atención necesarios. ${ }^{32}$ Sí examina la información factual que ellos aportan y critica esta información en base a su probabilidad. Todo parece indicar que Bacon juzga los hechos relatados por las fuentes a partir de sus propios presupuestos, de lo que le parece que es probable que haya ocurrido en base a su saber y su experiencia en el ámbito de la política. Bacon fue bien explícito a este respecto al señalar que el juicio de la historia no ha de pedirse a los monjes ni a los hombres de escritorio, ya que tales personas "son testigos poco fieles de las cosas": pueden tener una bella retórica, pero poco juicio y parcialidad. Por el contrario, los más capacitados para interpretar los hechos políticos del pasado son los gobernantes mismos, los hombres que trabajan en la función pública y los que conocen de cerca las dificultades y misterios de los asuntos públicos. ${ }^{33} \mathrm{Ha}$ de tenerse en cuenta, además, que Bacon compuso la historia de Enrique VII inmediatamente después de su caída en desgracia y que lo hizo con la clara intención de demostrarle al Rey su gran capacidad y conocimiento de los asuntos públicos. Así como antes lo había hecho ejerciendo diversos roles en la corte, ahora lo haría a través de un texto histórico cargado de aplicaciones políticas. ${ }^{34}$

\footnotetext{
${ }^{32}$ Marvil (1976) 160-161; Anderson (1984) 177-182; Kiernan, Introducción de OFB VIII, xxxix-xl. Levy (2004) 258 sostiene que los errores son más bien el resultado de que Bacon trabajó de memoria y no podía chequear sus fuentes ni los archivos públicos.

${ }_{33}^{3}$ In felicem memoriam Elizabethoe (SEH VI 291). Wormald (1993) 58-60.

${ }^{34}$ A este respecto es bien expreso lo que Bacon manifiesta en su carta a Diego de Gondomar en SEH XIV 285. Vd. Kiernan, Introducción de OFB VIII xlii-xliii.
} 
Varios pasajes de la History of Henry VII dan muestras de cómo Bacon interpretó, analizó, criticó y recreó sus fuentes para adaptarlas a la finalidad de su narrativa. Por razones de brevedad, tomaremos como muestra un episodio muy relevante en el relato cual es la conspiración de Lambert Simnel. ${ }^{35}$ El reinado de Enrique fue sacudido por varias conspiraciones que Bacon registra con especial cuidado, aplicando su experiencia personal como investigador de diversos complots contra la Corona inglesa. Una de las conspiraciones contra Enrique VII tuvo lugar entre 1486 y 1487, cuando Lambert Simnel, un niño de origen humilde nacido en Oxford, fue entrenado por el sacerdote Richard Simon (Symonds), para reclamar el trono de Inglaterra haciéndose pasar por el Conde de Warwick, Eduardo Plantagenet. En 1486 había corrido el rumor de que Warwick, que estaba prisionero en la Torre de Londres, había muerto. Ante esta circunstancia Simon montó el fraude. ${ }^{36} \mathrm{La}$ impostura fue tan exitosa que Simnel llegó a ser coronado en Dublín como Eduardo VI en noviembre de 1487. A partir de ese episodio se dio una serie de conflictos políticos y enfrentamientos armados entre sus seguidores y los súbditos fieles al Rey Enrique.

Bacon sostiene que los relatos históricos de la conspiración son tan "insustanciales" que hacen "poco creíbles" los orígenes y las circunstancias en las que la conspiración tuvo lugar. Por eso, cree que necesario construir un "juicio a partir de las cosas mismas, tal como ellas se iluminan unas a otras, y extraer la verdad, cuanto podamos, de la mina." ${ }^{37}$ En primer lugar, Bacon expone todo lo que le parece creíble de los registros de sus fuentes. Que alguien engañe a los demás para obtener el trono es creíble, porque es algo que ha ocurrido muchas veces tanto en el pasado remoto como en el reciente. También lo es que un hombre vil se embarque en semejante empresa, ya que suele suceder que las personas de clase baja se imaginan "grandes cosas", en especial cuando son "intoxicados" por los dichos de otros. En segundo lugar, Bacon registra lo que le parece poco creíble del relato de sus fuentes. Nos dice que no es plausible que alguien como Simon, que no había conocido personalmente a Warwick, pensara que podía prepararlo a Simnel para imitarlo exitosamente. De todo ello, Bacon infiere que alguien poderoso perteneciente al entorno de la corte tuvo que haber estado detrás de Simon para ayudarlo a preparar al impostor. ${ }^{38}$

Luego de esta serie de consideraciones, Bacon conjetura que "lo más probable" es que el motor principal de la impostura de Simnel haya sido Isabel

\footnotetext{
${ }^{35}$ Henry VII (OFB VIII 17-32).

${ }^{36}$ Analizan el caso Marvil (1976) 164-166, Anderson (1984) y Tinkler (1996) 244-245.

${ }^{37}$ Henry VII (OFB VIII 17).

${ }^{38}$ Henry VII (OFB VIII 18).
} 
Woodville, viuda de Eduardo IV, suegra de Enrique VII y tía de Eduardo Plantagenet. En favor de esta conjetura, a lo ya considerado Bacon suma una serie de razones a las que presenta como conocidas con certeza. En primer lugar, es un hecho "cierto" que Isabel Woodville era una mujer que ya había intervenido en negociaciones y conspirado contra Ricardo III. ${ }^{39}$ También es cierto que estaba disconforme con la situación actual de su hija en calidad de consorte de Enrique. Por otro lado, concluye Bacon, nadie estaba en mejores condiciones que ella para entrenar a Simnel. Su intención última y la de quienes colaboraron en el fraude no era tanto que el impostor se convirtiera en monarca sino más bien derrocar a Enrique VII.

Finalmente, Bacon presenta un hecho que a su juicio es el que por encima de cualquier otro "fortifica esta conjetura": ni bien se descubrió la impostura, una de las primeras decisiones que tomó Enrique fue mandar a encarcelar a Isabel Woodville y expropiarle sus bienes. Lo hizo reuniendo un consejo secreto que, sin mediar ningún proceso legal, la acusó, por un lado, de haber abandonado el asilo político junto con sus hijas en 1484, aceptando las condiciones impuestas por Ricardo III, y, por otro, de consentir que su hija mayor pudiera casarse con Ricardo en 1485, contrariando el acuerdo que había sellado años antes con la familia de Enrique, según el cual éste desposaría a su hija mayor una vez que derrocara a Ricardo. Todo eso hace pensar, según Bacon, que la verdadera causa del castigo aplicado a Isabel Woodville no fueron las razones explícitas -que eran graves por sí mismas-, sino más bien una oculta razón todavía más grave — su complicidad en la conspiración de Simnel—, que, sin embargo, el Rey no quiso hacer pública por diversos motivos. ${ }^{40}$ Para reforzar aún más su conjetura acerca de la responsabilidad de Isabel en la conspiración de Simnel, Bacon añade que "una prueba no menor" de que algo permaneció en secreto es que Simon mismo, luego de haber sido aprehendido, no fue ejecutado ni sometido a un juicio público, como sí les había ocurrido a muchos otros sacerdotes juzgados por traiciones de menor envergadura. A esto se suma, continúa Bacon, que cuando murió el Conde de Lincoln, miembro de la familia de Isabel Woodville, Enrique VII se lamentó porque guardaba la esperanza de llegar a conocer por su intermedio todo lo que estaba verdaderamente involucrado en el caso. ${ }^{41}$

\footnotetext{
${ }^{39}$ Cabe agregar que esto es algo registrado por numerosas fuentes de la época.

${ }^{40} \mathrm{Al}$ introducir esta conjetura, Bacon sólo en parte sigue a Speed, quien expresa la sospecha de que detrás del castigo extremo impuesto a Isabel Woodville debía existir una razón oculta. Vd. Henry VII, OFB VIII, Comentarios, 319-320.

${ }^{41}$ Henry VII (OFB VIII 18).
} 
Además de este ejercicio de interpretación conjetural de la causa última de la conspiración, Bacon habitualmente introduce otras causas a lo largo de los distintos eslabones de la historia. Esas causas no tienen antecedentes en sus fuentes y son producto de las especulaciones elaboradas por el propio Bacon. Por ejemplo, Bacon nos ofrece una serie de causas por las cuales Simon llevó al niño Simnel a Irlanda para perpetrar la conspiración: en primer lugar, porque dado que el verdadero Eduardo había vivido en Inglaterra, la impostura tenía que llevarse a cabo lejos de allí, donde había más chances de que se descubriera el fraude; en segundo lugar, porque en Irlanda la casa de York gozaba de mayor simpatía; en tercer lugar, porque Enrique VII no se había ocupado lo suficiente de designar en Irlanda funcionarios de su confianza que reemplazaran a los del reinado de Ricardo III, cosa que debería haber hecho tanto debido a la simpatía de los irlandeses hacia los York como debido a la proclividad típica de ese país a los cambios políticos. Según Bacon, el Rey erróneamente creía que sus victorias políticas le habían asegurado la fidelidad de Irlanda. Así las cosas, cuando Simnel llegó a Irlanda, todo estaba "preparado para la revuelta y la sedición, casi como si se hubiera dispuesto y complotado por anticipado." ${ }^{\text {2 }}$ A diferencia de lo que ocurría cuando postulaba como conjetura muy probable que la responsable última de la conspiración de Simnel fuera Isabel Woodville, en estos casos, donde aborda las razones por las cuales Simnel fue proclamado rey en Irlanda y no en otro territorio, Bacon expone las causas de estos hechos sin más, como si fueran ciertas.

Todo parece indicar que en la History of Henry VII las causas son presentadas como probables cuando discrepan con lo que relatan otras historias consagradas como autoridades en su época y son presentadas como ciertas cuando no polemizan con ninguna autoridad. En los casos en los que Bacon no está de acuerdo o tiene dudas acerca de la información proporcionada por sus fuentes despliega una argumentación que, luego de cuestionar la información disponible como poco plausible, expone una conjetura sostenida por una serie de pruebas, que en muchos casos hacen uso de técnicas características de la retórica forense. No vemos en este procedimiento (ni tampoco en otros contextos) una gran preocupación por buscar en fuentes primarias o secundarias información adicional precisa de lugar, tiempo y circunstancia que aporte pruebas en favor de su conjetura, ${ }^{43}$ como sí lo habría hecho en el caso de la historia natu-

\footnotetext{
${ }^{42}$ Henry VII (OFB VIII 19-21).

${ }^{43}$ Muy raramente Bacon introduce nueva información factual no proporcionada por sus fuentes y obtenida de documentos de primera mano. Tal es el caso de la mención de los presentes que en 1496 el Papa Alejandro le hizo llegar a Enrique VII en agradecimiento por su adhesión a la Santa Liga (Henry VII OFB VIII 123, nota p. 427-428). Cabe agregar que esta brevísima información adicional, que ocupa apenas un par de líneas, no parece tener gran relevancia en el relato.
} 
ral. Lo que hace predominantemente es seleccionar hechos ya conocidos y reinterpretarlos a partir de su propia experiencia en la función política, de manera tal de sostener su conjetura a través de esa especulación. ${ }^{44}$

En cambio, cuando Bacon reproduce la información de sus fuentes o introduce una lectura de las causas de los hechos relatados por ellas a partir de su propia inventiva y sin polemizar con otras narrativas, no se ve en la necesidad de cuestionar ni de fundamentar nada y, en consecuencia, tanto la repetición de lo consignado por las fuentes secundarias como la invención de las causas se presentan como simples certezas. Así, por ejemplo, cuando Bacon relata el episodio por el cual fue encarcelado William Capel (Caple), no sólo registra las circunstancias del delito narradas por sus fuentes, sino que además agrega información sobre la personalidad de Capel que explicaría las causas que condujeron a su acción transgresora. Sin embargo, al introducir esta novedad, Bacon no aduce ninguna fuente $y$, al parecer, tampoco se basa en material documental alguno. ${ }^{45}$ Algo similar sucede con los discursos ficticios que, siguiendo la costumbre de la historiografía humanista, Bacon incorpora en su narrativa, sea ornamentando, reescribiendo o modificando profundamente los discursos relatados en sus fuentes, siempre con el fin de dar claves causales de los acciones de la historia, que sirven indirectamente para brindar directrices y guías para la acción política. ${ }^{46}$ Por otro lado, cabe agregar que, por lo general, Bacon no introduce ni "inventa" nuevos acontecimientos. ${ }^{47}$ Por el contrario, las innovaciones que incorpora, sea mediante discursos ficticios, pensamientos y monólogos internos, o sea mediante descripciones de los hábitos y las personalidades, generalmente están al servicio de explicar las intenciones de los actores que intervienen en los episodios consignados por sus fuentes.

\section{Historia, poesía y ficción}

La postulación de las causas, el ejercicio de la conjetura y la introducción de discursos ficticios nos conecta con las reflexiones en el seno de la historio-

${ }^{44}$ Tinkler (1996) 245-247.

${ }^{45}$ Henry VII (OFB VIII 160-161).

${ }^{46}$ Ejemplos en este sentido en Henry VII son los discursos de William Warham (OFB VIII 9091; nota p. 387) y de Perkin Warbeck (OFB VIII 104-107; nota p. 406) en el que Bacon transforma un discurso indirecto relatado por Speed en un discurso directo de gran relevancia. Vd. Anderson (1984) 181.

${ }^{47}$ Según mi conocimiento, la única excepción a esta generalización, podría ser un breve episodio relatado por Bacon que no aparece en ninguna de las fuentes y que algunos especialistas consideran que puede ser apócrifo. Vd. Henry VII (OFB VIII 147-148, nota p. 449). 
grafía Tudor sobre la relación entre la historia y la poesía. Durante el Renacimiento, la historia y la poesía estaban originalmente asociadas, en tanto disciplinas lingüísticas, con la retórica y la gramática. El vínculo entre ellas se reforzaba por el hecho de que ambas trataban sobre la virtud y el vicio en los asuntos humanos, de modo que estaban a su vez conectadas con la filosofía moral y con una finalidad didáctica. De acuerdo con la mirada de la época, la historia narra hechos y circunstancias particulares, mientras que la poesía abarca patrones generales de acción abstraídos de los casos singulares gracias a la intervención de la imaginación. El historiador está obligado a describir eventos complejos y ofrecer un relato fiel de lo que realmente ocurrió. Por ello, las enseñanzas morales no se extraen de un relato histórico tan fácilmente como se extraen las ficciones proporcionadas por la poesía. ${ }^{48}$ Como consecuencia de ello, en el siglo XVI para muchos la historia era una disciplina de rango inferior a la poesía. Algunos llegaron a sostener que para alcanzar sus fines de enseñanza moral, la historia debía incorporar el uso de la imaginación tomando como modelo la poesía. Tal es la posición de Philip Sidney, un intelectual de gran relevancia en la Inglaterra isabelina, cuyo círculo Bacon frecuentó durante su juventud. ${ }^{49}$

En su $A$ defense of poetry (1595), Sidney se niega a hacer un elogio de la historia porque considera que esta disciplina no ofrece los ejemplos necesarios para derivar preceptos morales. La práctica histórica mejora precisamente cuando usa los "métodos" de la poesía al exponer buenos ejemplos morales o postular las causas de los hechos históricos. Sidney cree que los historiadores necesitan valerse de la imaginación para lograr que los hechos históricos sirvan para brindar enseñanzas prácticas. Lo mismo sucede cuando la historia se propone conjeturar las causas de los hechos que, por lo general, están lejos de ser evidentes. En función de ello, a veces el historiador no debe basarse en la verdad de los hechos, sino en su verosimilitud, como lo hacen los poetas. ${ }^{50}$ Cuando la fidelidad a los hechos, los detalles y las precisiones son dejados de lado, el historiador se libera y está en condiciones de inventar las causas de los hechos y los ejemplos didácticos.

Al igual que Sidney, Bacon considera que la poesía está regida por la imaginación. ${ }^{51}$ Sin embargo, a diferencia de Sidney, considera que son la memoria y la experiencia las facultades principalmente ligadas con la historia, al punto

\footnotetext{
${ }^{48}$ Levy (2004) 242-243.

${ }^{49}$ Levy (2005) 204-206. Sobre Bacon y el círculo de Sidney vd. Martin (1992) 26-27.

${ }^{50}$ Levy (2004) 244.

${ }^{51}$ Buena parte de sus reflexiones sobre la poesía tienen paralelos con expresiones de Sidney. Vd. Advancement of Learning (OFB VI 274-276).
} 
que expresamente presenta la historia y la experiencia como una misma cosa. ${ }^{52}$ La historia, por el hecho de ser un repositorio de experiencias, necesita ser menos controlada que la filosofía o la poesía. Según las palabras de Bacon, tiene "menos de su autor que de las cosas mismas." 53 Por otro lado, la poesía, junto con la historia y la filosofía, es una de las tres principales ramas del saber (learning), por lo cual supone una vinculación de la mente con lo real. Pero, al ser fundamentalmente gobernada por la facultad de la imaginación, es una actividad que, si bien es discursiva, no constituye un reflejo fiel de las cosas. La imaginación no está atada a las leyes de la materia y puede combinar o separar a gusto los componentes de la realidad. ${ }^{54}$ De ahí que Bacon, en cuanto a la materia que trata, defina la poesía como una "historia ficticia"55 y una "imitación de la historia" según el gusto del poeta. ${ }^{56}$ Al igual que la historia, la poesía trata sobre individuos (Bacon no habla aquí de "patrones generales de conducta" como sostenían muchos en su tiempo), pero a diferencia de ella, estos individuos son imaginados a semejanza de los rememorados por la "historia verdadera". Dado que la imaginación es libre, a veces la poesía va más allá de los límites de la imitación estricta de los individuos representados por la historia y compone como quiere eventos que no existen ni existieron en la realidad. ${ }^{57}$ En cuanto a su forma discursiva la poesía admite variantes, ya que se puede expresar en prosa o en verso, al igual que la historia. Así es como la "narración verdadera" puede contarse en versos, mientras que el discurso ficticio puede exponerse en prosa. Por todo ello, Bacon reconoce haber colocado a la poesía "al lado de la historia" en su clasificación del saber. ${ }^{58}$

Bacon distingue tres clases de poesía: narrativa, dramática y parabólica. ${ }^{59}$ La poesía "narrativa" o "heroica" es caracterizada como una mera imitación de la historia, una versión de la historia humana, cuyos temas son por lo general el amor y la guerra, con el aditamento de las licencias que se le permiten a la imaginación poética. Al parecer, Bacon se refiere en este caso a historias ficticias tales como las de Amadís de Gaula, Huon de Bourdeaux o del rey Arturo,

\footnotetext{
${ }^{52}$ De augmentis scientiarum (SEH I 495).

${ }^{53}$ The History of the reign of King Henry VIII, King Edward, Queen Mary, and part of the reign of Queen Elizabeth (SEH VI 18). Este escrito es un breve fragmento, compuesto alrededor de 1602, que anuncia la intención de Bacon de escribir una historia de Inglaterra de largo alcance, que nunca llegó a componer.

${ }^{54}$ Sobre los múltiples usos y aplicaciones de la imaginación en Bacon vd. Wallace (1943) y Corneanu y Vermeir (2012).

${ }_{55}^{5}$ Advancement of Learning (OFB IV 73); De augmentis scientiarum (SEH I 494).

${ }^{56}$ De augmentis scientiarum (SEH I 518).

${ }^{57}$ De augmentis scientiarum (SEH I 494).

${ }^{58}$ De augmentis scientiarum (SEH I 315).

${ }^{59}$ De augmentis scientiarum (SEH I 518-521); Advancement of learning (OFB IV 74-76).
} 
que atribuyen acciones fabulosas a "héroes imaginarios". ${ }^{60}$ En cuanto a su valor de verdad histórica estos relatos difieren notablemente de aquellos que cuentan las verdaderas hazañas de Julio César o de Alejandro Magno, ${ }^{61}$ así como las observaciones supersticiosas y los experimentos fantasiosos que registran algunos libros de magia difieren de la genuina magia natural en cuanto a la verdad de la naturaleza. En coincidencia con Sidney, Bacon afirma que la poesía ha dado algo de "satisfacción" a la mente humana en lo que la naturaleza de las cosas se la ha negado, porque el mundo real no siempre está en consonancia con las expectativas humanas. En efecto, los actos y los eventos relatados por la "historia verdadera" no tienen la magnitud necesaria para satisfacer las aspiraciones de la mente, por eso la poesía inventa hechos grandiosos y heroicos. De la misma manera, en el relato histórico, el éxito y el fracaso de los hombres no necesariamente se corresponden con sus méritos morales, por ello, la poesía postula una retribución más justa y más acorde con la providencia divina. La "historia verdadera" representa acciones y eventos ordinarios y comunes, mientras que la poesía los transforma al agregarles características extraordinarias y variaciones inesperadas. En suma, concluye Bacon, la poesía sirve a la magnanimidad, a la moralidad y al deleite. Por eso con razón se ha dicho que participa de la divinidad, ya que mediante la imaginación eleva la mente humana, adaptando a sus deseos las apariencias de las cosas. Por el contrario, la razón la hace rebajarse para que sea la mente la que se adapte a la naturaleza de las cosas. ${ }^{62}$

Por su parte, la poesía "dramática" o "representativa" se monta en el teatro. Es una historia hecha visible que representa las acciones como si estuvieran presentes, mientras que la historia las ofrece como ellas son en realidad, es decir, como hechos ocurridos en el pasado. Cuando se la cultiva correctamen-

\footnotetext{
${ }^{60}$ Estas historias legendarias circulaban en Inglaterra en diversas versiones, como por ejemplo The most excellent and pleasante book, intituled Treasurie Amadis of Gaule (1572) de Thomas Paynell, traducido por N. de Herbery; Le Morte d'Arthur (1485) de Thomas Malory y The ancient historie of Huon of Bourdeaux (1601). Cabe señalar que el juicio de Bacon sobre la historia del Rey Arturo de Bretaña es más moderado en Henry VII (OFB VIII 17) donde admite que, a pesar de sus componentes fabulosos, la historia tiene una base verdadera. Vd. Wormald (1993) 58.

${ }^{61}$ Advancement of Learning (OFB IV 89); De augmentis scientiarum (SEH I 573); Cogitata et visa (SEH III 600).

${ }^{62}$ Advancement of Learning (OFB IV 73-74); De augmentis scientiarum (SEH I 518-519). Es importante notar una diferencia entre las versiones del Advancement of Learning (1605) y De augmentis scientiarum (1623). Toda esta reflexión sobre la poesía que vincula el pensamiento de Bacon con el de Sidney, en el Advancement aparece en la presentación de la poesía en general, mientras que en el De augmentis el mismo párrafo está añadido en la descripción de la poesía narrativa. De tal manera, según la última versión de la teoría baconiana de la poesía, el carácter "divino" sería propio de la poesía narrativa (y no de toda clase de poesía).
} 
te, esta clase de poesía teatral promueve la virtud y la disciplina en su audiencia.$^{63}$ Por último, la poesía "parabólica" es presentada en el Advancement of Learning como una narración dedicada a expresar un propósito o idea particular. ${ }^{64}$ En el texto paralelo presentado en De augmentis scientiarum, Bacon profundiza su análisis y la define como "una historia con imágenes que transporta a los sentidos los contenidos del intelecto". ${ }^{65}$ Esta clase de poesía fue muy corriente en la Antigüedad, como lo muestran, por ejemplo, las fábulas de Esopo, los enigmas de la Esfinge, los apotegmas de los Siete Sabios, los jeroglíficos y, sobre todo, los relatos mitológicos. Una de las utilidades que han tenido los mitos antiguos fue ilustrar y hacer accesibles mediante imágenes sencillas conceptos filosóficos difíciles tanto en lo que se refiere a la naturaleza como a la moral y la política. ${ }^{66}$

Esta breve presentación de los tipos de poesía nos permite advertir que si bien la historia y la poesía constituyen dos ramas distintas del saber, esta distinción epistemológica no impide que tengan importantes elementos en común. El principal elemento compartido por la historia y la poesía consiste en que ambas se refieren a hechos particulares. ${ }^{67}$ Por eso es posible decir que la poesía es un tipo especial de historia: si bien no es una memoria de los hechos del pasado, su materia prima siguen siendo hechos particulares (aun cuando Bacon asume que su valor didáctico reside precisamente en que estos hechos pueden ser semejantes a otros hechos). Por otro lado, poesía e historia comparten el propósito de proporcionar algún tipo de enseñanza. La historia ofrece enseñanzas fundamentalmente vinculadas con la acción política, mientras que el espectro didáctico de la poesía es mucho más amplio.

Hay un punto, sin embargo, donde claramente la poesía se distingue de la historia: el discurso poético tiene un valor estético que proporciona placer a los hombres, mientras que la historia está exenta de tal valor. Bacon se interesa por dejar en claro que el historiador no debe preocuparse por componer textos especialmente bellos. Finalmente, el punto más significativo que separa la his-

\footnotetext{
${ }^{63}$ Advancement of Learning (OFB IV 74); De augmentis scientiarum (SEH I 518-519)

${ }^{64}$ Advancement of Learning (OFB IV 74).

${ }^{65}$ De augmentis scientiarum (SEH I 518).

${ }^{66}$ Advancement of Learning (OFB IV 74-75). En De sapientia veterum (1609) Bacon presenta sus propias interpretaciones de numerosos mitos clásicos. Recientemente esta obra fundamental del corpus baconiano ha sido traducida al español. Vd. Bacon (2014). Para un estudio clásico sobre este tema vd. Rossi cap.3.

${ }^{67}$ En esto Bacon se distancia de Aristóteles para quien la historia es "más filosófica y superior a la historia", dado que tiene la capacidad de "expresar lo universal" mientras que la historia sólo expresa lo particular. Vd. Aristóteles, Poética, 51a36-51b7. Para un estudio de la posición de Bacon en relación con la tradición aristotélica vd. Schuler (1992).
} 
toria de la poesía consiste en que, al menos en teoría, la historia presenta hechos reales mientras que la poesía expone hechos ficticios. He aquí donde la teoría de Bacon en cierto punto colisiona con su práctica como historiador, en la que, como hemos visto, la ficción propia de la poesía constituye un factor importante en la construcción de la narrativa histórica, particularmente a la hora de postular (sea como certezas o como conjeturas) las causas de los hechos "reales y verdaderos" en términos de las intenciones y las condiciones psicológicas de los actores intervinientes, o también al incorporar discursos ficticios según la costumbre humanista.

\section{Conclusión}

Algunos autores han señalado que la teoría de la historia de Bacon, al hacer una distinción de las ramas del saber de acuerdo con las facultades de la mente, separó tajantemente la historia de la imaginación y de la razón, y la confinó al ámbito de la memoria. ${ }^{68}$ Sin embargo, como acabamos de indicar, en la propuesta baconiana la historia y la poesía están mucho más cerca de lo que puede parecer en un primer momento. Esta proximidad se acentúa mucho más en la práctica de Bacon como historiador, donde la memoria, la razón y la imaginación actúan conjuntamente. Bacon llena lagunas, reinventa discursos, define perfiles psicológicos, postula imaginativamente móviles e intenciones en los actores que no tiene manera de constatar en los hechos y, aunque pudiera hacerlo, no lo haría por considerarlo innecesario. En su afán por dar enseñanzas efectivas a los hombres dedicados a la vida pública, está dispuesto a seleccionar, combinar, completar, alterar, exagerar y manipular la información brindada por sus fuentes, a partir de su propia inventiva. En esta construcción de la narrativa histórica no solamente intervienen la memoria y los sentidos, sino que a ellos se suman la imaginación dirigida a la producción de una enseñanza útil para la acción política en el presente $y$, por supuesto, la razón que construye argumentos para darles plausibilidad a sus conjeturas y sus especulaciones presentadas como certezas. Esta práctica de la historia produce una evidente fusión de la especulación imaginativa con el registro memorístico y empírico histórico. ${ }^{69}$

Una de las consecuencias de este abordaje es la compleja manera en que Bacon presenta los hechos históricos en términos de certeza o de probabilidad.

\footnotetext{
${ }^{68}$ Kelley \& Sacks (1997) 3.

${ }^{69}$ Levy (2004) 253-254, 257; Bushnell (1997) 195.
} 
Su versión de la historia de Enrique VII introduce ficciones como causas ciertas y presenta como probables causas que otras fuentes consideran ciertas. En la exposición de Bacon la calificación de los hechos como probables y ciertos obedece a criterios que no se derivan de la crítica textual y contextual de las fuentes en búsqueda de su verificación objetiva, sino de la "prudencia", de la experiencia política del historiador que interpreta los hechos y les atribuye determinadas causas. Lo que convierte en cierta una conjetura del historiador o en probable un hecho relatado como cierto por un tercero es su conformidad o no conformidad con el acervo teórico del que dispone el historiador como resultado de su experiencia en la vida política, de su saber práctico. Por otro lado, Bacon hace tales distinciones particularmente cuando cuestiona los relatos de sus fuentes y tiene la necesidad de desmentir o corregir la información que ellas aportan. En los otros casos relata todas sus conjeturas como certezas.

Sin embargo, al parecer Bacon no piensa que al introducir deliberadamente sus ficciones está mintiendo, contrariando sus mandatos metodológicos, ni falseando la realidad. Antes bien, en su práctica historiográfica asume una concepción particular de verdad: la verdad de la ficción. ${ }^{70}$ ¿En qué consiste esa verdad? Bacon parece concebir que la verdad de la historia civil no es la mera correspondencia de la mente con los hechos del pasado sino una verdad de índole activa, que abarca el saber hacer en el ámbito de la política, en paralelo al saber hacer en el ámbito de la naturaleza (registrada en la historia natural y la filosofía natural), y en perfecto acuerdo con la estricta vinculación que Bacon continuamente establece entre vida activa y vida contemplativa. Esta particular "verdad" que debe reflejar la historia civil "perfecta" consiste en el modo en que se da la relación entre ciertas causas y sus efectos: en cuáles son las consecuencias de determinados cursos de acción del pasado, del presente y del futuro.

\section{Bibliografía}

Judith H. Anderson, Biographical Truth: The Representation of Historical Persons in Tudor-Stuart Writing (New Haven, 1984).

Aristóteles, Poética, edición trilingüe por Valentín García Yebra (Madrid, 1974)

Francis BACON, El Avance del Saber. Introducción de Alberto Elena, traducción y notas de Ma. Luisa Balseiro (Madrid, 1988).

Francis BACON, La sabiduría de los antiguos. Estudio preliminar, traducción y notas de Silvia Manzo (Madrid, 2014).

${ }^{70}$ Anderson (1984) 189. 
Francis BACON, The Advancement of Learning, edited with introduction, notes and commentary by M. Kiernan, in The Oxford Francis Bacon, vol. IV, (Oxford, 2000).

Francis BACON, The Historie of the raigne of King Henry the seventh, and other works of the 1620s, edited with introduction, notes and commentary by M. Kiernan, in The Oxford Francis Bacon, vol. VIII (Oxford, 2012).

Francis BACON, The works of Francis Bacon, edited by J. Spedding, R. L. Ellis, and D. D. Heath., 14 vols.. Reproducción anastática de la edición de Londres, Longman and Co., 1857-1874 (Stuttgart -Bad Cannstatt: Friedrich Frommann Verlag-Günther Holzboog, 1989).

Edwin B. Benjamin, "Bacon and Tacitus", Classical Philology, 60 (1965), 102-110.

Edward B. BERRY, "History and Rhetoric in Bacon's Henry VII", en SeventeenthCentury Prose: Modern Essays in Criticism, ed. Stanley E. Fish (Nueva York, 1971), 281-308.

Wilhem Busch, England under the Tudors, translated by A.M. Todd (Londres, 1895).

Bushnell, REBECCA, "Experience, truth and natural history in early English gardening books" en Kelley, D. R., \& Sacks, D. H., eds., The historical imagination in early modern Britain: History, rhetoric, and fiction, 1500-1800. (Washington, 1997) 179-209.

Stuart Clark, "Bacon's Henry VII: A Case Study in the Science of Man", History and Theory, 13 (1974), 97-118.

Sorana CORNEANU, \& Koen VERMEIR, "Idols of the Imagination: Francis Bacon on the Imagination and the Medicine of the Mind", Perspectives on Science, 20 (2012), 183-206.

Leonard DEAN, "Sir Francis Bacon's Theory of Civil History-Writing”, English Literary History, 8 (1941), 161-183.

Arthur B. Ferguson, "The Non-Political Past in Bacon's Theory of History", Journal of British Studies, 14 (1974), 4-20.

George HupPERT, The Idea of Perfect History: Historical Erudition and Historical Philosophy in Renaissance France (Urbana y Chicago, 1970).

Donald. R. Kelley \& David H. SACKS, "Introduction” en id., The historical imagination in early modern Britain: History, rhetoric, and fiction, 1500-1800 (Washington, 1997).

Fritz J. LEVY, Tudor historical thought, (Toronto, 2004). Primera edición California 1967.

Fritz J. LEVY, "Francis Bacon, The Advancement of Learning and Historical Thought" en Solomon, J. R., \& Martin, C. G., eds., Francis Bacon and the refiguring of early modern thought: Essays to commemorate The Advancement of learning (16052005), (Aldershot, 2005) 203-211.

Silvia MANZO, "Francis Bacon's natural history and civil history: a comparative survey", Early Science and Medicine, 17 (2012), 32-61.

Julian Martin, Francis Bacon, the State and the Reform of Natural Philosophy, (Cambridge, 1992).

Jonathan MARWIL, The trials of counsel: Francis Bacon in 1621 (Detroit, 1976).

George H. NADEL, "History as Psychology in Francis Bacon's Theory of History", History and Theory, 5 (1966), 275-287. 
Nicholas Popper, "An Ocean of Lies: The Problem of Historical Evidence in the Sixteenth Century", The Huntington Library Quarterly, 74 (2011) 375-400.

Paolo Rossi, Francis Bacon: de la magia a la ciencia, trad. Susana Gómez López, (rev. de la ed. original de 1957) (Madrid, 1990).

Frank Smith Fussner, The Historical Revolution: English Historical Writing and Thought 1580-1640 (Londres, 1962).

J. H. M, SAlmon, "Stoicism and Roman Example: Seneca and Tacitus in Jacobean England", Journal of the History of Ideas, 50 (1989), 199-225

Barbara J. Shapiro, Probability and Certainty in Seventeenth-Century England: A Study of the Relationships between Natural Science, Religion, History, Law and in Literature (Princeton, 1983).

Robert M. ScHuler, "Francis Bacon and Scientific Poetry", Transactions of the American Philosophical Society, New Series, 82 (1992), 1-65.

John F. Tinkler, "Bacon and History," en Markku Peltonen, ed., The Cambridge Companion to Bacon, (Cambridge, 1996), 232-259.

Brian VICKERS, "Introduction" en Francis Bacon, The History of the Reign of King Henry VII and Selected Works, ed. Brian Vickers (Cambridge, 1998).

Karl R. Wallace, Francis Bacon on Communication and Rhetoric (Chapel Hill, 1943).

Daniel R. Woolf, "Erudition and the Idea of History in Renaissance England", Renaissance Quarterly, 40 (1987), 11-48.

Daniel R. Woolf, "John Seldon [sic], John Borough and Francis Bacon's 'History of Henry VII', 1621”, The Huntington Library Quarterly, 47 (1984), 47-53.

B.H.G Wormald, Francis Bacon: History, Politics and Science: 1561-1626 (Cambridge, 1993).

Perez Zagorin, Francis Bacon (Princeton, 1998).

Silvia MANZO

Instituto de Investigaciones en Humanidades y Ciencias Sociales (UNLP CONICET). Facultad de Humanidades y Ciencias de la Educación, Universidad Nacional de La Plata, Argentina

manzosa@yahoo.com.ar 